\title{
sigloveinte@lit.mex. Recorrido en 4 escalas ${ }^{1}$
}

\section{twentiethcentury@1it.mex. A Journey in 4 Stops}

\author{
Fernando Curiel Defossé \\ Universidad Nacional Autónoma de México \\ Instituto de Investigaciones Filológicas \\ Seminario de Edición Crítica de Textos \\ fcuriel632@yahoo.com
}

\begin{abstract}
RESUMEN
En términos generales, el artículo tiene el objetivo de ofrecer una propuesta para la construcción de una historia de la literatura mexicana del siglo xx, cuyos presupuestos se configuran y establecen a lo largo de un recorrido, en el que, entre otras cuestiones, se reflexiona en torno a las Humanidades, sus particularidades y sus disciplinas; en cuanto a estas últimas, cabe anticipar que el foco de interés recae en la literatura y la historia, en particular, la historia intelectual. En este sentido, se retoman los planteamientos relacionados con la labor del historiador y, por ende, de la historiografía expuestos por Dominick LaCapra en La historia y sus límites. Posteriormente, se hace una revisión tanto de los factores políticos, sociales y culturales como de las aportaciones y carencias de los estudios teórico-críticos que han intervenido en la conformación de un registro de nuestras letras del pasado siglo. Por último, se presenta una división de dicha centuria literaria en cuatro escalas o periodos para poner en marcha esta propuesta.
\end{abstract}

\section{Palabras Clave}

Humanidades, historia de la literatura mexicana del siglo xx, historia intelectual, Dominick LaCapra, teoría y crítica literarias.

\section{Abstract}

Generally speaking, the objective of this article is to present a proposal for the construction of a Mexican literature history of the 20th century. During this period foundations take shape and get established throughout the journey where, among other issues, it reflects around the Humanities, its particularities and dis-

\footnotetext{
${ }^{1}$ Entre otros escritos alusivos, sirve de antecedente al presente ensayo: "Historia y literatura" (Curiel, 2018: 9-14, dentro de la sección "Reflexiones en torno a...", incluida en el volumen II, número 1 de esta misma revista (an)ecdótica.
} 
ciplines. Regarding those disciplines, it's important to establish that the focal point rests on literature and history, specifically intellectual history. In that sense, the text borrows the ideas of Dominick LaCapra about the role of the historian and therefore of the historiography set forth in his book: History and its Limits. Subsequently the text reviews both the political, social and cultural factors and the contributions and shortcomings of the critical theory studies responsible for the configuration of a record of our literature from the past century. Lastly, the text proposes the division of the literary Century in four stops, or periods to put this proposal in motion.

\section{KEYWORDS}

Humanities, history of Mexican literature of the 20th century, intellectual history, Dominick LaCapra, literary theory, literary critic.

RECEPCIÓN: 06/08/2019

ACEPTACIÓN: 22/09/2019

Para Tito Piazza y Emmanuel Carballo, in memoriam a Fernando Tola de Habich

Acercarse a los procesos culturales desde distintos escorzos, requiere de un ejercicio diorámico de observación que permita ubicar, de la manera más certera, a hombres y circunstancias, a obras y propósitos y, por eso mismo, explique los ejes vertebrales de una nación.

Ana Elena Díaz Alejo

\section{Atento aviso}

耳 lijo, como previo y especial pronunciamiento, una precisión. Dos en realidad. UNo me sorprendería, sin embargo, que se tomaran ambas como provocación. Protesto que no es ni por pienso el objetivo. Sí, en cambio, situar el "lugar" desde el que rindo mi propuesta.

La primera precisión advierte que, a diferencia del propósito, y no pocas veces fruto espléndido, de la investigación científica, léase la exactitud, la investigación humanista se reconoce (debería reconocerse) inexacta. No digo: falsa; no digo: mendaz. Y su fruto, asimismo, espléndido. Me explico. Por la naturaleza de su materia poliédrica y fluida - el Hombre y sus fulguraciones y desfiguros - , su ratio es la tentativa, la aproximación; dicho esto en sentido positivo, de encomio incluso. Mejor dicho: suma de tentativas, aproximaciones, que, en afortunada expresión de Alfonso Reyes - aquí invitado 
por derecho propio, como lo son Benjamin, Steiner, Candido, Said, entre otros-, conduce al "milagro de la comprensión". ${ }^{2}$

La "comprensión", por ende, que no el saber exacto, o si se prefiere apodíctico, traba, arma a las Humanidades. Trabazón, armado - aclaro contundente-: documentados, sustentados con fundamentos sólidos y argumentos lógicos, las más de las veces.

Añoso reclamo, por cierto, es el de que esta diferencia específica, orgánica, entre saberes humanistas y saberes científicos, sea reconocida sin rebozo por los órganos oficiales ejecutores de evaluaciones y dispensadores de estímulos y becas. Reclamo no atendido hasta la fecha. ${ }^{3}$

$\mathrm{Y}$, derivada de la anterior, tenemos esta otra nota distintiva del cultivo de lo $\mathrm{Hu}-$ mano, su ser y hacer, crear, atesorar, rescatar, pensar, memorar y memorizar. ${ }^{4}$ Hablo de la ausencia - prohibición me atrevería a decir- de la objetividad a toda costa. Si por objetividad se entiende lo que define a un conocimiento externo, impersonal, neutral, aséptico, apátrida. Matemática de las matemáticas.

Constreñido a las Humanidades, digamos clásicas y contemporáneas, tenemos lo siguiente. La exigencia de marcos teóricos, del rigor metodológico, de la infatigable heurística, del trasiego y la crítica de fuentes; no alcanzan, empero, para eliminar - no tendrían por qué- la subjetividad. Subjetividad, insisto, connatural al empeño filológico, filosófico, histórico, jurídico, sociológico, antropológico... O a su suma multidisciplinaria.

Así pues: las Humanidades, si ciencias, "ciencias inexactas"; y el humanista, investigador subjetivo, dispensado de objetividad sine qua non.

Aduzco que el fin de la "Temporada" - dicho en el sentido autoritario de "Último grito" de la Moda - del Estructuralismo y la Cliometría, de tal o cual "Giro", de la Condición Posmoderna a rajatabla, entre otros desencantos, apuntan todos ellos, flagrantes, en esa dirección.

${ }^{2}$ Sentencia Reyes: "Sumando varias perspectivas, varios sistemas de referencia; reduciendo unos a otros; teniendo en cuenta la relatividad de todos ellos, y su interdependencia para un ojo omnipresente que acertara a mirar el cuadro desde todos los ángulos a la vez, nos acercamos al milagro de la comprensión" (1941: 3-4).

${ }^{3}$ Post scriptum. En esta vena, el 13 de septiembre de 2018, tres colegas - Virginia Guedea, Guillermo Hurtado, Humberto Muñoz - y yo suscribimos la proclama "Reconocimiento, encomio y defensa de las Humanidades", difundido en primera instancia electrónicamente (véase: http://www.iifilologicas.unam.mx/index.php?page=las-humanidades-en-el-conacytun-manifiesto).

${ }^{4}$ Véase Curiel, Guedea, Hurtado y Muñoz (2018). Una más precisa división entre las Humanidades de corte clásico y las Humanidades contemporáneas radicaría en el cultivo de lo Humano de las primeras, y el cultivo de lo Humano y su entorno natural y social de las segundas. 


\section{Antecedente inmediato}

Tengo presente, en todo momento, Letras mexicanas del XIX. Modelo de comprensión histórica (2009), la notable contribución de Belem Clark de Lara a nuestro desvelo. Seguí de cerca su construcción laboriosa; celebré, celebro - agua a mi molino- la voz "comprensión" en vez de cualquier otra posible. Como veremos, no pocos de sus presupuestos y postulados tienen cabida en mi propio modelo. Únicamente anticipo, subrayándolo, el pleno acuerdo con el aserto de que, en nuestro medio académico, respecto a la historia de la literatura nacional, no hemos trabajado colegiadamente ni en sus "supuestos", ni en sus "hipótesis", ni en sus "procedimientos" (Clark: 18). Pero no me adelanto.

\section{Criba del pasado o principal marco teórico}

Tengo por tropas de refresco, de los Estudios Literarios - en sus dimensiones crítica, ecdótica e histórica-, los trabajos inscritos en la llamada Historia Intelectual (véase Curiel, 2015). Suma intra y multi disciplinaria. Notable y numeroso es el elenco de sus cultivadores. No obstante, y diré por qué, privilegio en esta ocasión un nombre, el del norteamericano Dominick LaCapra. ${ }^{5}$ De suerte que, para entrar en materia, me valgo de su libro más reciente, de los traducidos al idioma español: La historia y sus limites (2016). Y no creo que huelgue subrayar que la elección de un reciente libro de historia, y de historia intelectual en particular, débese al contenido de este ensayo, que no es otro que la historia - historia intelectual - literaria.

En su síntesis del pensamiento de LaCapra, Alicia García Ruiz, la muy competente prologuista, recuenta tres ejes de dicho pensamiento. A saber: la representación del pasado "es una práctica social de producción de sentido"; el entendimiento crítico del "estatuto de la objetividad"; y "cómo y con qué herramientas de racionalidad es posible afrontar la experiencia traumática en el nivel social” (13-14).

De indudable aplicación en este trabajo son los ejes primero y segundo; y el tercero cabría si se juzga que la actual crisis nacional - Sociedad y Estado, Poderes y Partidos—, que insisto en reputar Decadencia, bordea ya el trauma. ${ }^{6}$

\footnotetext{
${ }^{5}$ Sin desdeñar, por supuesto, las aportaciones de Elías José Palti, Carlos Altamirano, Donald R. Kelley, François Dosse, Jean Sirinelli, Robert Jauss, Robert Darnton, Alphonse Dupront, Yves-Charles Zarka, Daniel Roche, entre otros, tal y como lo asiento en sigloveinte@lit.mx.Amplio tratado de perspectiva generacional (Curiel, 2008: 25-45). Libro cuyo título usufructúo, en parte, en el del presente ensayo.

${ }^{6}$ El 1 de julio de 2018, con motivo de las elecciones presidenciales, un partido de reciente creación, MORENA, triunfa en toda la línea sobre el PRI, el PAN y el PRD, por citar los partidos mayores. Su candidato, Manuel López Obrador, expriista y experredista, había anunciado
} 


\section{sigloveinte@lit.mex. Recorrido en 4 escalas}

Prosigo. Asimismo, en su prólogo, Alicia García fija la premisa del quehacer del autor de La historia y sus límites:

la labor del investigador histórico está abocada a la necesidad de teorizar siempre sobre su propia actividad, porque la escritura histórica es un formidable dispositivo de producción social de sentido. El historiador está obligado a tomar conciencia de una especial forma de responsabilidad. Para LaCapra teorizar no consiste sólo en un escrutinio interno sobre la epistemología implícita en la práctica de la historiografía, ni tampoco en preocupaciones de carácter exclusivamente metodológico. Además de lo anterior, esa necesidad de teorizar que reclama LaCapra apunta sobre todo hacia aquello que Max Horkheimer denominó como función social del conocimiento (14).

Horkheimer, añado, distingue entre una teoría tradicional y una teoría crítica. De lo que se trata es del concepto dominante sobre los hechos. Porque el hecho no es un simple datum ajeno, independiente de su observación, sino, por el contrario, "una construcción que determina su relevancia en función del interés del observador" (García: 14). Las distintas observaciones, agrego, de la Naturaleza humana (civilización, cultura, sociedad, ciudad, artes, educación, literatura). Hechos son, para nosotros, los productos literarios. Primarios: poesía, novela, cuento, ensayo, dramaturgia. Secundarios: crítica, rescate, historia, teoría. En su "observación" - lectura, interpretación- nos implicamos de manera inevitable.

Abunda la prologuista:

La teoría tradicional, con su reclamación de objetivismo, se concebiría como un espejo que refleja la sociedad tal cual es. La teoría crítica, en cambio, señalaría que es la sociedad misma quien sostiene su propio espejo y se plantea, por tanto, cuál puede ser el grado de deformación del mismo, en función de la imagen que se quiere ver o los intereses involucrados en esta representación (García: 14).

Tal es la razón por la que LaCapra:

presta una cuidadosa atención a las consecuencias sociopolíticas del papel del historiador y de la historiografía en sociedad. El estudio de lo histórico aspira a establecer qué aspectos del pasado son recordados o relevantes, pero esto implica la necesidad de discutir los propios criterios de selección, así como la manera en que se efectúa la representación de tales hechos (García: 14-15).

una Cuarta Transformación de la historia del país; transformación pacífica, a diferencia de las tres anteriores, Independencia, Reforma y Revolución, sustentadas en luchas armadas. Queda por elucidar hasta qué punto, tamaña profética promesa, desdibuja, supera mejor dicho, la muy evidente de decadencia nacional. 
“¿Por qué?”: pregunta, se pregunta justificadamente reiterativa la propia García Ruiz, adelantándose al lector. Y responde - respuesta, anticipo, que comparto y a la que volveré más adelante- : "Porque la labor del historiador es una actividad social donde se ponen en juego tanto la determinación de cuáles son los hechos pretéritos como la caracterización de a qué aspectos cruciales de las sociedades contemporáneas afectan". Aspectos, puntualiza la autora, "que pueden abarcar desde sus premisas más profundas de convivencia hasta las más arraigadas fuentes de identidad” (15). Observación, avanzo también, que igualmente comparto y que retomaré más adelante. En suma, lo que anima a LaCapra, señala García Ruiz, es "la representación del pasado como práctica social de producción de sentido (15)".

Llamo la atención sobre conceptos tales como: función social del conocimiento; el hecho como construcción; observación interesada; observador comprometido; afectación de la sociedad contemporánea; comunidad; identidad. Conceptos abstractos que traduzco, aterrizo al significado de la Literatura del xx como faro mexicano, rutilante entre oscuridades borrascosas y resistencia cultural.

\section{Historia viva}

Permítaseme abundar un poco más. En efecto, la labor del historiador - el social, el político, el literario - no se agota en el acopio de datos y su correspondiente catalogación, sino que "conlleva siempre la tarea de comprensión" (García: 15). Vocablo este último intencionalmente expresado en cursivas. Agua, asimismo, a mi molino.

Tarea de comprensión que reviste ciertas características: "La historiografía no es el mero registro de un pasado inerte sino una interpretación viva sobre él, dinamismo gracias al cual el presente se vincula de hecho, y no sólo como un proceso imaginario, con el pasado" (García: 15). Tarea ésta de elaboración de la "memoria colectiva", por demás compleja, que implica por fuerza - sin que esto signifique que se me contradiga en esencia - objetividad; en realidad, una "idea de objetividad". Porque, en su definición, entran en juego argumentos e intereses de diversos grupos. De ahí que Paul Ricoeur hable de "un conflicto de interpretaciones". Interpretaciones - atención al plural - que demandan un "delicado equilibrio entre una inevitable carga de juicios previos (no necesariamente prejuicios, en sentido peyorativo) que el investigador lleva consigo en cuanto miembro de una sociedad y el máximo de información precisa que sea posible recabar y contrastar" (García: 15$).^{7}$

${ }^{7}$ Divisa que, sin duda, suscribirá el Seminario de Investigación sobre Historia y Memoria Nacionales, del que, asimismo, formo parte. 


\section{Objetividad, subjetividad adentro}

La verdad física, química o matemática puede aducir objetividad irrestricta (hasta en tanto, diría Thomas Kuhn, el autor de La estructura de las revoluciones científicas, no se imponga un nuevo paradigma en la Física, la Química e incluso la Matemática). Otra es la situación de la verdad histórica. Veamos:

Puesto que la propia sociedad es modificada por los conocimientos que vamos desarrollando sobre ella, el estatuto de la objetividad sólo se puede comprender adecuadamente partiendo del hecho de que lo que denominamos "verdad histórica" es un artefacto discursivo modelado según uso dialéctico del lenguaje que cada grupo activa o reprime según sus propios intereses (García: 16).

¿Semejante mutación, variabilidad, torna el discurso histórico, la "verdad histórica", en ficción, ficción desasida de referentes contextuales? En modo alguno. Más bien, se relativiza, o intrinca, el concepto de objetividad. Marcado por la complejidad. Tanto que, al igual que se distingue entre legalidad y legalismo, habría que distinguir entre objetividad y objetivismo.

¿Ficción la historia, en LaCapra? Sí. Pero no cualquier tipo de ficción. El que la historia establezca relatos no le autoriza "cualesquiera relatos" (García: 16). LaCapra, precisa García Ruiz, al par que se cuida de no incurrir dócil en el pensamiento del día - último grito de la intolerante moda académica, anoto yo-, evita difuminar la frontera entre historia y literatura. Aunque en el entendido de que la historia no es sólo invención, sino que guarda férreo compromiso con la "reivindicación de verdad"; quehacer, aquí sí, marcado por la objetividad (¿o el objetivismo?). Objetividad entendida como verosimilitud. Mas no carente, añado, de la subjetividad que imprimen tanto el observador como - entre varios - el elegido método de observancia.

Ahora bien: por límite no se entiende, en LaCapra, limitación, sino el horizonte conceptual de la intervención histórica y la forma que ésta adopta (García: 15).

\section{Conclusión telegráfica de lo hasta aquí dicho}

Así pues, tenemos, por un lado, la comprensión - reitero las cursivas - como última ratio; y, por otro, el reconocimiento, por sobre la penetración heurística en el proceso de investigación — archivos, legajos, corpus, trabajo de campo- , de la impronta subjetiva del investigador humanista y social.

Y dejo para otra ocasión el comentario minucioso de dos de los ensayos contenidos en el libro de LaCapra en cita: "Cómo articular la historia intelectual, la historia cultural y la teoría crítica" y "Tropismos de la historia intelectual". Síntesis de un 
pensamiento en marcha, autocuestionado, abierto a temas tan diversos como la condición postsecular, la violencia, los nexos entre el hombre y el animal, la animalidad humana, etcétera. Por ahora, sólo subrayo, en el primero de los mencionados ensayos, el llamado de atención a la contextualización extrema, excluyente:

Para el aficionado a contextualizar en un estrecho marco historicista, la contextualización se identifica sin problemas con la interpretación histórica de un modo tal que margina o evita la forma en la que los textos interactúan con los contextos y requieren una interpretación receptiva, incluyendo formas de implicación afectiva por parte del investigador con relación al "objeto" de investigación (LaCapra: 37).

Y, en el segundo ensayo destacado, también vinculado con la ilimitada contextualización, el riesgo de cosificar el pasado, privándolo de futuro - el nuestro construyéndose en el presente, añado- - El autor recuerda cómo a partir de los años ochenta del siglo anterior, junto con otros colegas, se afanó en reformular la Historia Intelectual, así como su relación con la Historia Cultural y con la Historia Social. Empeño desarrollado en dos frentes. Contra una historia de las ideas formalista y sin arraigo, y contra interpretaciones sociales o socioculturales reduccionistas. Por el contrario, se apostaba a la explicación de cómo funcionaban los textos o praxis significadores, y

cómo estos interactuaban - cuestionando a veces - con diversos contextos pertinentes de producción, circulación y recepción, incluyendo nuestro propio contexto, en el que ciertos aspectos de los textos podrían plantear cuestiones a nuestros presupuestos a la hora de leerlos. El contextualismo o historización puros, que identifican acríticamente interpretación histórica con contextualización, niegan de hecho la dimensión contestataria y transformativa de los textos (en sentido amplio) y la forma en que estos plantean a los lectores exigencias de interpretación sensible, exigencias que vienen modeladas por las inquietudes actuales a la vez que posiblemente nos permitan aprender del pasado [...] El contextualismo radical también puede basarse en el dudoso concepto de interpretar algo en sus propios términos y época, como si el pasado no estuviera, en sí mismo, implicado en sus pasados, plagados de controversia e incertidumbre y abierto a sus posibles futuros; no fijado en ámbar o como un objeto de conocimiento aproblemático y "cartografiable" que explica plenamente y da significado a los textos (LaCapra: 213).

Disculpo la prolijidad, pero solicito se tenga todo lo anterior - en resumidas cuentas - como principal "marco teórico" de la propuesta que aquí pongo a consideración/discusión. ${ }^{8}$ Sintetizo: la teorización como algo que va más allá de lo epis-

\footnotetext{
${ }^{8}$ Sin omitir, tampoco, y no sobra la aclaración, de un lado, los avances de Reyes en "Mi idea de la Historia" y en El deslinde, y de otro, el distingo entre Historia e Historiografia. Por la primera comprendo: hechos, episodios y cronologías; y por la segunda: perspectiva, interpretación, escritura. Trátese de historia e historiografia políticas, sociales, económicas o -insertas en la Historia Intelectual- literarias. Nuestro asunto.
} 
temológico y lo metodológico; la historia, historia viva; su constructo, individual y colectivo; la implicación, afectiva y social, de su ejercicio; las consecuencias que apareja en lo individual y lo colectivo. Y la erradicación del simplismo en el aspecto, clave, del contexto - los contextos de los textos literarios.

\section{El campo literario}

El asomo a las Humanidades, su naturaleza, el saber proteico que genera, a la inescapable subjetividad de su cultivo y al carácter comprometido de sus disciplinas, en este caso la Historia - acontecimiento y signo-, tienen aquí un claro propósito. Hablo del examen de los estudios de la literatura tanto en el ancho - pero para nada ajeno - mundo como en nuestra patria. Presupuestos, a su vez, inexcusables para mi objetivo: la formulación tentativa, una aproximación, entre otras posibles, de una historia de la literatura mexicana del siglo $\mathrm{xx}$, de sus condiciones de posibilidad, para ser preciso - o si se quiere, en este particular caso, para ser "exacto"- Tales estudios fijan el horizonte conceptual de la reconstrucción temporal - todo un siglo- de la Literatura patria.

\section{Disparador}

En carta a José Luis Martínez de fecha 25 de marzo de 1946, estimulada por la lectura de "Algunos problemas de la historia literaria", ensayo que su destinatario había publicado en el número de febrero del mismo año de la revista El Hijo Pródigo, Alfonso Reyes celebra que el texto de Martínez: a) consista en todo "un programa para desarrollos futuros, una verdadera hipótesis de trabajo"; y b) asuma que "el criterio principal [en una] historia literaria es la "trascendencia"” (Reyes, 1946: 78 y 79, respectivamente).

¿Pero qué se entiende por tal, por trascendencia?, plantea de inmediato el autor de Visión de Anáhuac. "¿La influencia inmediata, o la influencia mediata o 'resurrección?? ¿O todo eso que, sin ser 'influencia', se llama en términos técnicos 'fortuna' de una obra? ¿O bien la persistencia de la obra precisamente como rareza y cosa insólita, que no engendró o no pudo engendrar familia? ¿O todo ello junto?” (carta citada en Clark y Curiel: 104-105).

En ánimo de encarar el "todo ello junto" que señala Reyes, reducirlo a cifra, mejor dicho, de tiempo atrás, con la guía imborrable de la "trascendencia" — una novela, un poema, un ensayo no se agotan en su "textualidad", reverberan hacia la literatura misma y hacia la sociedad-, establezco tres vías posibles de historia de la literatura. La de los autores — de corte psicológico y aun psiquiátrico-, la de las 
obras - con prescindencia de autores y lectores, de fuerte perfume metafísico- y la del sistema literario, que subsume de entrada las dos anteriores. En ejercicio de congruencia, me inclino por esta última. La vía más completa por omnicomprensiva de todas y cada una de las fases de lo literario: Creación, Producción, Distribución, Recepción, Certificación, Catalogación. ${ }^{9}$ Con sus correspondencias internas y externas.

¿Qué correspondencias externas? Creación, Producción y Distribución con la Industria Editorial y la Lectura; Recepción y Certificación con el mundo académico, el periodístico y el burocrático; y la Catalogación con las labores de la memoria literaria - a fin de cuentas cultural.

\section{Premisa(s)}

Modestamente, yo, asimismo, me propongo en este "paper" - como se estilaba decir no ha mucho - una producción social de sentido, al modo en que este último desvela a LaCapra y que su prologuista ensalza. Preciso, gustoso. Ni más ni menos que el sentido de una de las altas lumbres del siglo xx mexicano, su Literatura. Siglo de por sí, en el campo simbólico, dimensión que suele olvidarse o menospreciarse, de dos revueltas culturales, una entre el orto del Porfiriato y los inicios de la Revolución Mexicana, protagonizada por el Modernismo y el Ateneo de la Juventud, y otra en la década del sesenta, protagonizada, a su vez, por varios equipos intelectuales. Equipos a los que me referiré más adelante.

Únicamente anticipo que privilegio al autor colectivo o social frente al individual. Y que, en el primer rubro - tal es mi punto de vista-, considero, asimismo, en tanto grupo, a los Consejos Editoriales de las más señaladas revistas durante ambas movilizaciones culturales; inclusive, a colecciones monotemáticas, como por ejemplo la de México y lo Mexicano, impulsada por el grupo Hiperión, y Autobiografias Precoces, que conjuntó al editor-empresario Martín Luis Guzmán, a su colaborador Emmanuel Carballo y a las nuevas voces de una literatura marcada por la "tradición de la ruptura". O la "ruptura" a secas.

Digo sin dubitaciones ni tapujos, "revueltas culturales", por abarcar, respectivamente: una, la literatura, las artes gráficas y la pintura a finales del siglo XIX y las

\footnotetext{
${ }^{9}$ Belem Clark alude, en su propuesta de un modelo de "comprensión histórica", a un trabajo previo en el que participamos la historiadora Guadalupe Curiel Defossé, la misma autora de Letras mexicanas del XIX y el dicente, "Para una historia de la literatura mexicana de dos siglos", contribución a un homenaje al historiador Álvaro Matute, coordinado por José Ortiz Monasterio. Los planteamientos ahí formulados sirven de antecedente a lo aquí expuesto. Por ejemplo, que entre "historia literaria", centrada en obras y autores, o "historia de la literatura", relativa al entero sistema literario, optamos por la segunda. Y que de las "clases" de historia posible, lo hacemos por la "intelectual" (Clark, 2009: 43).
} 
primeras décadas del xx; y la otra, la literatura, las artes todas y el pensamiento crítico a lo largo de los 60's.

Juan José Tablada, Jesús E. Valenzuela, Pedro Henríquez Ureña, Alfonso Reyes, Julio Torri, Ramón López Velarde, entre otros, en la primera revuelta; Carlos Fuentes, Sergio Pitol, Rosario Castellanos, Juan García Ponce, Salvador Elizondo, Inés Arredondo, José Agustín, Gustavo Sainz, entre los principales, en la segunda. En cuanto al capítulo mexicano del Boom, otro ingrediente sesentero, éste parece agotarlo el autor de Cambio de piel; aunque luego respetaría, si alguien reclama para dicho casillero, los nombres de Sergio Pitol, Vicente Leñero, Jorge Ibargüengoitia o mi tocayo Del Paso.

\section{Panorama mundial}

Independientemente de las contriciones, "crudas", y tics suicidas al interior, sobre todo, de la Novela y de la Dramaturgia, a partir de cierto momento de la segunda Posguerra se produce un movimiento que trastoca el orden literario, hasta entonces aceptado como una jerarquía de primero, segundo y tercer grado. Correspondiendo el primer grado a la Creación, en poesía y en prosa; el segundo, supeditado, a la Crítica - también transitada por creadores, un T. S. Elliot o, para no ir tan lejos, un Julio Torri-; y el tercero, a la Teoría, no menos supeditada a la Creación y a la Crítica, pero empeño, asimismo, de algunos creadores - poetas y narradores - dados al pensamiento literario, un Goethe en Alemania, un Reyes en México. Huelga decir que el Ensayo, género anfibio - o si se quiere, en un sentido positivo si lo hubiere, bipolar -, se desplazaba como "Juan por su casa" en los tres grados mencionados.

De esta suerte estamental, hasta que se produce una especie, no dudo en llamarlo así, de Golpe de Estado, merced al cual la Teoría desplaza con malas artes a la Creación y a la Crítica. Golpe de Estado que termina por consagrar - rematar - el establecimiento, en el pensamiento occidental, de la llamada Condición Postmoderna (véase Lyotard). No poca responsabilidad cabe en este fenómeno a la fiebre de los "Giros" en el medio académico. ${ }^{10}$ Únicamente tareas de zapa en el orbe literario, como el rescate y la edición de textos, la ecdótica, escaparon indemnes a la hiperteorización por momentos avasallante.

Por el contrario a lo ocurrido en la Filología, la disciplina de la Historia también entró de lleno al juego de la Teoría a toda costa (mientras que, paradójicamente, dos de sus distinguidos miembros, Michel de Certeau y Hayden White, un francés y un norteamericano, se alzaban como excepcionales estudiosos de la narrativa, trasladando, con enorme éxito, a la escritura de la historia los recursos, los tropos, las figuras de la tradición literaria).

${ }^{10}$ Por ejemplo: Rorty (1990), Palti (1998), Ricoeur (1995) y Dosse (2004). 
Ahora bien: en cuanto a corrientes y tendencias teoréticas responsables de la inversión de factores aludidos — que en este caso altera el resultado-, si bien guardan principal lugar el Formalismo Ruso o el Criticism sajón, a la que se reconoce como dominante (¿y depredadora?) es a la que se engloba como French Theory, abigarrado conjunto en el que se disputan el cetro Foucault, Barthes, Kristeva, Derrida, etcétera (véase Cusset).

\section{Muertes en cadena}

Puede hablarse, in genere, en buena parte del siglo xx, de la Muerte de la Literatura (y, en contraposición, del Reinado del Texto, y "texto" puede ser cualquier cosa). O, más anecdóticamente, de decesos ocurridos, a mi juicio, en el siguiente orden fúnebre.

Muerte del Escritor de Carne y Hueso y múltiples señas de identidad, entre ellas, como raíz profunda - o marca de fuego-, una nacionalidad determinada; muerte del Autor, pues bastaba pulsar una tecla clave de la lengua, lengua por do se le contemple autorreferencial y autárquica, para que se desatara el discurso; muerte del Personaje, constreñido a mero Actante, no obstante aliar al escritor y al autor y dirigirse en primer término al lector; muerte de la Trama, o aquello de lo que la obra trata fundiendo contenido, argumento y lengua; y, el colmo, por último —ultimátum-, muerte del Sentido de lo Literario y, con ello, de su valía libertaria.

Me detengo en la última defunción mencionada, azuzada - no disculpo el término - tanto por la Teoría de la Recepción como por la Teoría de la Obra Abierta. Llevadas al extremo de un libertinaje por el cual cada lector lee lo que se le ocurra y cada autor impone cuantos desenlaces tenga a bien. Cuando, en realidad, la misma anfibología del lenguaje con la que se teje poesía y prosa conoce límites, y poesía y prosa imponen su lógica interna, inescapable. En otras palabras, ni toda lectura es válida, pertinente; ni toda creación goza del derecho de pernada.

Desde luego, puede añadirse la otra debacle, ya no en el ámbito del pensamiento, sino en el específicamente editorial. Ámbito entregado, incluso antes de que los editores de raza hagan mutis, despejen el campo a Ejecutivos formados en la industria restaurantera, de la lencería o del show biz, a la antirromántica Rentabilidad a toda costa (caiga quien caiga, la Literatura en primer término). El Corporativo trasnacional como dueño y señor de la edición.

De tamaña mutación me ocupo, tangencialmente, en el libro sigloveinte@lit.mx. Amplio tratado de perspectiva generacional - al que, reitero, debo la mitad del título del presente "paper"— y, de manera concreta, en el ensayo "Una especie en extinción". ${ }^{11}$

\footnotetext{
${ }^{11}$ El libro, el ya citado sigloveinte@lit.mx, se publicó como fruto del proyecto de investigación multidisciplinaria "1810-2010: la configuración del México moderno y contemporáneo",
} 


\section{Crónica de un contragolpe}

Discreto, un tanto avergonzado, vegetaba el reparo a la entronización de la Teoría, a la que se sumaban las auto-expedidas actas de defunción de la Literatura, cuando, en coautoría, dos físicos de profesión, Alan Sokal y Jean Bricmont, publican en Francia, en 1997, el libro Impostures Intellectuelles, su frontal desenmascaramiento. Al año siguiente se traduce en Inglaterra y en Estados Unidos, edición esta última con la que me topo en la librería (¿Brentanos?) del Rivercenter de San Antonio, Texas. ${ }^{12}$ Y cuyo subtítulo no es otro que el de "Postmodern Intellectuals' Abuse of Science". Para ese entonces, más que el Poet, el Novelist o el Critic, Scholars como Jacques Lacan y Roland Barthes y Michel Foucault y Derrida, al frente de una considerable hornada, brillaban día y noche en el firmamento intelectual. Más aún que en la propia Francia, su culto ganó adoradores fervientes en la academia norteamericana (con algunos frutos en la nuestra). Lo que no dejaba de sorprender y molestar a Sokal y Bricmont.

Lo incuestionable es que mortífero estaba resultando para la Literatura la pócima de "veritable intoxication with words" y la "soberb indifference to their meaning". ${ }^{13}$ Más adelante, aparece A Reader's Manifesto de B. R. Myers, que arremete contra el best-seller de culto norteamericano, el frecuentado por Paul Auster, Don DeLillo, Cormac McCarthy, etcétera. No sin razón llamé al libro de Myers "El Anti Auster".

\section{Panorama local}

Por motivo principalmente de espacio, limito mi exposición al ámbito de la Universidad Nacional Autónoma de México, dejando por ahora fuera otros organismos de investigación literaria. En 1999, en momento de un "paro" de labores en la UnAM, que parecía iba a clausurarla - auto-invasión degenerada en invasión-, un grupo de investigadores del Instituto de Investigaciones Filológicas (IIFL) fraguamos, en el exilio,

auspiciado por la Coordinación de Humanidades de la UNAM. El ensayo se recogió en Hábitos (Curiel, 2005: 231-253) — reconozco haber simplificado en demasía para su título aquello de que "El hábito hace al monje" - y, revisado y ampliado, se incluyó en Novo conoce el mar y otros ensayos (Curiel, 2019: 155-177).

${ }^{12}$ Para la edición inglesa, Profile Books, 1998; para la norteamericana, Picador USA Edition, 1998. Hay traducción al español de Joan Carles Guix Vilaplana, bajo el título Imposturas intelectuales, Paidós, 1998.

${ }^{13}$ El contragolpe tenía cola. Uno de los dos autores, Sokal, había hecho llegar para su severísimo dictamen - dos filtros, creo-, a Social Text, la más copetuda revista gringa en estudios culturales, una amañada parodia posmodernista que ponía por los suelos a Euclides y a Newton. Dictaminadores y directivos, en montón, muerden el anzuelo. El pastiche se publica, y entre clarines y atabales, Sokal descubre la trampa. Se arma la de Dios padre. 
un seminario de reflexión sobre el quehacer filológico. Así nació el libro colectivo $\mathrm{Fi}^{-}$ lología mexicana, que, de haberse agotado ya su tiro, ameritaría reeditarse.

De "Filología Literaria" me ocupé al alimón con la Dra. Belem Clark de Lara. Intento, juzgo que bien logrado, de documentar la aventura de nuestra Casa de Estudios, en aras de la investigación, la docencia y la difusión literarias. Quehacer atento al artículo $1 .^{\circ}$ de la Ley Orgánica (1945), que exige privilegiar las condiciones y problemas nacionales.

Punto de partida: la creación, en 1956, del Centro de Estudios Literarios (CEL). Directamente, originado en el Instituto de Investigaciones Lingüísticas y en el Centro de Estudios Filosóficos; e, indirectamente, en un seminario de literatura mexicana integrado por profesores de la Facultad de Filosofía y Letras (FFYL), y los trabajos de la historiadora Clementina Díaz y de Ovando, orientados al rescate editorial de autores mexicanos esenciales. Obra aherrojada a la sazón en hemerotecas y archivos privados.

Vale la pena detenerse en el designio del CEL naciente:

El progreso de la literatura y de la lengua en un determinado país estará siempre condicionado por la medida del impulso que los especialistas sean capaces de darles a las empresas literarias y lingüísticas. No sólo es precisa, para que la literatura de un pueblo llegue a su madurez, la fecunda pero desordenada producción literaria de sus escritores [...] Indispensable es también, junto al más vigoroso ejercicio creativo, otro más vigoroso y difícil en ocasiones: el trabajo ordenador, orientador, axiológico y, en última instancia, creativo en modo diferente [...] La creación literaria requiere, en efecto, de una constante conciencia de sí misma, paralela a su desarrollo; de esa conciencia que es base de la verdadera crítica: la que depura y guía, y hasta cuando destruye lo hace con equilibrio imponderable (Clark y Curiel: 83-84).

Keywords: "madurez", "trabajo ordenador, orientador, axiológico y, en última instancia, creativo", "conciencia de sí misma".

Lejos estaba a la sazón el triunfo pleno de lo que he llamado Golpe de Estado Literario, el desplazamiento de la Creación y de la Crítica por la Teoría. Y si no se estipula en el designio recién citado la específica empresa historiológica - Historia e Historiografía-, se sobrentiende en las expresiones: ordenación, orientación, axiología, depuración, guía y, de manera enfática, conciencia ("conciencia de sí misma", reitero). Anuente estoy, además, en lo de que las tareas críticas - y añado teóricasson, pueden ser, deberían ser "creativas en modo diferente". Lo que, asimismo, vale para la historia literaria. ${ }^{14}$

${ }^{14}$ Tal y como prescribo en la pieza "El ensayo (crítico) literario. Primera entrega" (Curiel, 2019: 83-90). 


\section{Prosigo.}

En un principio ubicado en la Facultad de Filosofía y Letras, en 1960 se le fija al Centro (enriquecido con la donación de la Biblioteca de Julio Jiménez Rueda), como sede, la Biblioteca Central de Ciudad Universitaria. Seis años después, al ceL se le adscribe a la Coordinación de Humanidades $(\mathrm{CH})$.

$\mathrm{Al}$ interior del cel habían surgido inquietudes diversas. Y hacia 1969, se plantea de forma franca su conversión en Instituto de Investigaciones Literarias. Cabe destacar que, ahora sí, uno de los objetivos expresamente señalados al organismo en cierne se refiere a las bases para elaborar la gran historia de la literatura mexicana, que hasta la fecha hace falta.

Bien. En 1945, año de la Ley Orgánica; en 1956, año de creación del CEL; en 1960, año en que ocupa un espacio en la Biblioteca Central; en 1966, año en que se adscribe a la CH; y en 1969, año en que se demanda su paso a Instituto de Investigaciones Literarias; la ausencia de historia - historias mejor dicho - de nuestras letras formaba parte, claramente, de los "problemas nacionales". ¿Sigue inscrita hoy, 2020, en tamaña apremiante, estratégica, lista? Sin lugar a dudas.

Inquietudes y disyuntivas se resuelven con la aprobación, por parte del Consejo Universitario el 4 de octubre de 1973, de la creación del Instituto de Investigaciones Filológicas; anfictionía de las filologías hispana, clásica y amerindia. En 1986, entra en vigor su Reglamento Interno.

Ahora bien: tocante a la específica Filología Literaria, en 1977 inicia sus labores, como complemento del Centro de Estudios Literarios, el Seminario de Poética, con el propósito del "estudio del fenómeno literario en toda su complejidad, en su relación con las demás manifestaciones culturales y con la historia. Tal esfuerzo no privilegiará algún método particular, pero pretende realizarse siempre a través de enfoques teóricos rigurosos" (Memoria UNAM 1994).

Al Centro de Estudios Literarios, por su parte, quedan como líneas de investigación: Historia literaria; elaboración de artículos, antologías y monografías sobre autores, corrientes, generaciones, escuelas de los periodos colonial, siglos XIX y xx; Literatura Comparada; elaboración de estudios que examinen la ocurrencia de fenómenos literarios entre nuestra y otras literaturas; edición de obras completas de autores mexicanos; diccionarios de literatura; rescate de materiales bio-bibliohemerográficos para la historia de la literatura mexicana; índices y ediciones facsimilares de las más importantes revistas literarias de México; y análisis, clasificación e indexación de archivos de escritores mexicanos.

Pese a surgir como complemento, extensión, del Centro de Estudios Literarios, el Seminario de Poética, entre éste y dicho Centro seminal no se plantearon de entrada puentes de comunicación y colaboración. 
Y si la historia - historias - continuaba como asignatura pendiente del Centro de Estudios Literarios, del Instituto de Investigaciones Filológicas, de la Máxima Casa de Estudios en suma, uno de sus fundamentos, la ecdótica, guardaba un desarrollo intermitente. Lo que llevó, para su decidido y sistemático impulso, a la constitución, en 2010, del Seminario de Edición Crítica de Textos.

\section{Estado local del Arte}

En sentido estricto - iba a escribir "A calzón quitado" - , magra, casi inexistente es nuestra tradición histórico-literaria. Dentro y fuera de la UNAM. En cuanto a la temporalidad, me limito a los siglos XIX y Xx. Razón no sólo temporal, sino de contenido. ¿Cuál, grosso modo? De los Méxicos - Antiguo, Novohispano, Independiente-, parto del citado en último término. El México que, entre emancipaciones no sólo político-jurídicas - la literaria una de ellas - fulgores y derrumbes - y no olvidar que los terremotos de 1985 y 2017, un 19 de septiembre, fueron cataclismos tan naturales como sociales - traiciones, vueltas a comenzar, reexpedición de los "Espejitos" del siglo XVI, empieza su propia singladura en 1821, fin de la guerra emancipadora - si bien con un puñado de realistas enquistados, momentáneamente, en San Juan de Ulúa.

Magra tradición en el campo de la historia, en efecto. Para la parte del xIx, remito al recuento crítico que se hace en Letras mexicanas del XIX. Yo me constriño al siglo Xx. Informo lo que cosecho. En las primicias del siglo, el esfuerzo de instintiva, mas precisa historia intelectual del equipo de la formidable Antología del Centenario, comandado por Justo Sierra; la Historia de la literatura mexicana, debida en 1928 al ateneísta Carlos González Peña; y La historia de la literatura mexicana, dada a conocer en 1949 por José Luis Martínez. ${ }^{15}$ Tomo nota del proyecto de nuestro instituto, "Historia de las literaturas en

\footnotetext{
${ }^{15}$ A la de González Peña se anexó en 1969 un Apéndice elaborado por el Centro de Estudios Literarios de la UNAM. La segunda edición de la de Martínez, ahora en colaboración, no pudo rehuir el rijoso ambiente pos-68 en el campo cultural pautado por la lucha de facciones. En ese escenario, registro otro título aparecido en la segunda parte del siglo xx. Me refiero a La literatura mexicana del siglo XX de José María Espinasa, publicada en 2015 por El Colegio de México dentro de la Colección Historias Mínimas. La razón es sencilla: la juzgo parcial. Esto a la evidente luz de los acentos de su propio índice. Que, de las revistas, sólo figuren tres ligadas a Octavio Paz, sin duda uno de nuestros grandes polígrafos, pero, a fe mía, ni el único, ni el más grande - par entre pares - Taller, Revista Mexicana de Literatura y Plural, acaparando esta última ella sola el apartado "Los años setenta"; y que, de los nombres masculinos mencionados, sólo se anuncie al propio Paz, y entre los nombres femeninos sólo se anuncie a Elena Poniatowska. ¿Acaso, entre las revistas, no cuenta Revista Universidad de México? ¿Y, entre los escritores, no deberían figurar Rulfo o Revueltas? ¿Y entre las escritoras, Elena Garro o Rosario Castellanos no se llevan de calle a Poniatowska? En resumidas cuentas: ¿por qué no la
} 


\section{sigloveinte@lit.mex. Recorrido en 4 escalas}

México. Siglos XIX y Xx", en proceso, que, más que en el relato total de los fenómenos literarios nacionales, descansa, principalmente, en el análisis de sus procesos. De esta suerte se promete.

Mientras que la segunda parte del xx careció de nuevas historias dignas de tal nombre. Dicho esto, sin desdoro de serias aportaciones a la historia literaria mexicana, tales como los Capitulos de literatura mexicana de Alfonso Reyes, el recuento de entrevistas - entrevistas de fondo - de Emmanuel Carballo, Protagonistas de la literatura mexicana, y la propuesta de periodización debida a Carlos Monsiváis. ${ }^{16}$ Rimero al que habría que añadir, en la parte referida a las letras, la reflexión generacional que a partir de Altamirano verifica Tola de Habich, y el tomazo México en la cultura, editado en 1961 por la Secretaría de Educación Pública y prologado por su propio titular, don Jaime Torres Bodet. Y de singular valía resultan los trabajos, también en el aspecto generacional, realizados por Wigberto Jiménez Moreno y Luis González y González. ${ }^{17}$

\section{Reconocimiento especial}

Así pues, de justicia es apuntar como el más antiguo antecedente, en cuanto a propuestas temporales, la Antología del Centenario, una de las joyas del programa editorial de 1910. Dedicada a las letras a partir de la declaración de Independencia, comprendería varios tomos, de los cuales sólo llegó a publicarse el primer par por causa de fuerza mayor: el estallido de la Revolución Mexicana. Comandada por Justo Sierra, la empresa conjuntó a Luis G. Urbina y Pedro Henríquez Ureña en la parte intelectual y, en la parte material, a Nicolás Rangel. Los jovencitos Alfonso Reyes y Julio Torri desempeñaron labor voluntaria. Con sus letras, Henríquez Ureña señala:

No escrita aún la historia intelectual del país, nos faltaba la guía necesaria en el océano de papel que constituye la literatura mexicana. Tuvimos, pues, que orientarnos personal-

muestra de los que son, revistas y figuras masculinas y femeninas? Por confesión de parte tengo este pasaje de la introducción: "Tenemos un primer periodo, bien documentado y analizado, aunque estudiado con prejuicios ideológicos, y un segundo periodo disperso, con mucha historia por contar pero sin historiadores que lo hayan hecho, o bien demasiado atomizado en sus estudios, o todavía peor, sometido a los intereses de grupos de poder y reformulado cada cuarto de hora" (11-12). Y se expresa, por último, de forma claridosa: "Aquí se buscó encontrar para esta historia un tono de crónica, de relato, en el que las obras, más que los autores, tomarán el lugar de los personajes de esa novela" (12). Texto de historia literaria strictu sensu, por ende, no lo es.

${ }^{16}$ Periodización sustituta del enfoque generacional, en momento de agudo descrédito.

${ }^{17}$ Me ocupo de los más de estos autores en la ponencia "Ruptura y continuidad: periodos de la literatura mexicana del siglo xx", antecedente directo de este ensayo, presentada en la sesión correspondiente al año 2017 de la Cátedra Luis Mario Schneider. Intitulada Rupturas y continuidades. 
mente, con la escasa ayuda que prestan los ensayos de historia literaria producida entre nosotros (VII).

Keyword: historia intelectual.

De otra parte, se reconoce que no se trata de una "selección de verdaderas flores del arte literario" (Henríquez: Ix), sino de una "muestra cabal de las formas y de los géneros literarios cultivados en México durante el siglo XIX y lo que va del Xx" (IX). Lo bueno, lo mediano y lo malo. En su momento, José Luis Martínez especulará, basado en la división cronológica y temática del primer par (y único publicado, reitero), la posibilidad de tres pares más de volúmenes: III y IV para el periodo del Romanticismo y Adversidades, 1836-1867; V y VI para Concordia nacionalista, 1867-1889, y VII y VIII para el Modernismo y Realismo, 1889-1910.

Valdría la pena ahondar en dicha especulación temporal. En particular, por lo que se refiere a la temporalidad aquí considerada la etapa Modernismo y Realismo, 1889-1910.

\section{Propuesta, una entre otras posibles}

Es sobre el estado tanto externo como interno de los estudios literarios, antes expuesto, en el afán histórico de la literatura mexicana, que me permito poner a consideración las condiciones de posibilidad de una historia de la literatura patria del siglo Xx. Para la cual tengo presentes las aportaciones de González Peña, Pedro Henríquez Ureña, Martínez, Monsiváis, Jiménez Moreno, González y González, y Clark de Lara. Con el reconocimiento explícito de que, en diverso grado y con diversa deliberación, todos los citados incurren en la Historia Intelectual al destacar al autor social (Asociaciones Literarias, Generaciones, Promociones), el contexto de las obras, las revistas y polémicas, las redes, las distintas especies de recepción, etcétera, etcétera. De dependiente, antes que original por sus cuatro costados, debe estimarse en definitiva mi propuesta.

\section{Modesta proposición (a consulta)}

Invoco, y no es la vez primera que lo hago, dos nombres tutelares. Colocados en puntos extremos, sin conexión aparente alguna. Miguel de Cervantes, en primer lugar, cuando afirma sobre los Historiadores y la Historia: "habiendo y debiendo ser los historiadores puntuales, verdaderos y no nada apasionados, y que ni el interés ni el miedo, el rencor ni la afición, no les hagan torcer el camino de la verdad, cuya madre es la historia, émula del tiempo, depósito de las acciones, testigo de lo pasado, y aviso de lo presente, advertencia de lo porvenir" (62-63). Y, en segundo, Edmundo O'Gor- 
man, cuando, ya en las postrimerías de su fecunda labor, resume décadas de lecturas y disquisiciones sobre la Historia, de obras y reflexiones propias, del modo que sigue: "Quiero una imprevisible historia como lo es el curso de nuestras mortales vidas; una historia susceptible de sorpresas y accidentes [...] una historia tejida de sucesos que así como acontecieron pudieron no acontecer [...] una historia-arte, cercana a su prima hermana la narrativa literaria" (957-958)..$^{18}$

Don Miguel constata, sentencia. Don Edmundo propone un desiderátum. En el primer caso, habla sobre la Historia un escritor tan genial y original que inventa la Novela Moderna, y nos dice que la Historia es sinónimo del pasado, pero no antónimo del presente; que en sus veneros se guardan los hechos, añado que en estado latente para efectos de su interpretación; y que así como avisa sobre el presente especula sobre el futuro. Si bien es verdad que exhibe un escrúpulo objetivo — "cientifizante" - más propio de los historiadores positivistas del siglo XIX, pródigas precisiones las suyas, no obstante. Mientras que don Edmundo anhela, profetiza; concediendo lugar, empero, a excepciones y quebrantos, y curso a lo imaginario.

Pero de lo que hablan ambos autores es del Tiempo. Del Tiempo y sus meandros, cortes aquejados, más que de precisión tajante, de opacidad y porosidad. Tiempo cargado de literatura. Pues bien, del Tiempo, el del proceso literario mexicano del siglo xx - aceptaría la corrección del plural "procesos"-, se ocupa nuestra propuesta; una entre otras posibles, insisto. Propuesta que, además, no desdeña la sorpresa y el accidente, ni lo contra-factual, filos que destaca, particularmente, el polígrafo mexicano. ¿Cómo rehuir la sorpresa si la materia prima es el lenguaje, tan firme como huidizo, articulándose no pocas veces a su aire? ¿ $\mathrm{O}$ el accidente, fórmula secreta de no pocos prodigios verbales? ¿O la invitación, con los pelos de la burra en la mano, al quizá, al pudo ser? - al puro ser especulativo. ${ }^{19}$

Desagrego, desmenuzo la propuesta en: Temporalidad, conjeturales límite inferior y límite superior. Presupuestos, enunciación de los principales. Procedimientos o técnicas de operación. Y Escalas y/o cortes temporales, cuatro.

Veamos - probemos.

\footnotetext{
${ }^{18}$ No encuentro forma más elocuente de ensalzar la "inexactitud" y la "subjetividad", consustanciales de las Humanidades, de una de sus disciplinas, la Historia; si bien al tenor y con las características apuntadas - adelantadas - en este escrito. Investigación y saberes plenamente fundados.

${ }^{19}$ Por ejemplo, lo que pudo haber ocurrido si, en vez de imponer La región más transparente como fundadora, la crítica de la época hubiera reconocido - y celebrado - el itinerario de la Novela Urbana nacional a partir de Santa. Tradición, no sin sus rupturas, integrada por La sombra del caudillo, Casi el paraíso, Sol de octubre, Ojerosa y pintada, principalmente. Tema, el del itinerario de la Novela Urbana mexicana, en el que hoy por hoy me afano.
} 


\section{Temporalidad}

Límite inferior: 1898; límite superior: 2000. ${ }^{20}$ Procedo a la justificación - explicación - de uno y otro. Eslabón en la cadena de emancipaciones que se desatan en 1821-1824, con la consumación de la Independencia de España - emancipación primera: político-jurídica-; en 1898, con el Modernismo literario cifrado en la Revista Moderna, acontece la emancipación literaria de nuestras letras. Lo que marca lo subsecuente: influencias externas, sí, mas no dependencia, sumisión. Punto de arranque, dos años antes que el calendario general, del siglo xx literario.

Antecede, a la literaria, cabe señalarse, la emancipación de la sociedad colonial supérstite de 1821 a 1867, subdividida en la jurídico-económica de las Leyes de Reforma y la Restauración de la República; y la mental del positivismo, la fundación de la Escuela Nacional Preparatoria y la apertura a la laicidad. La suceden, a su vez, la emancipación de las artes plásticas merced a la muestra montada por la revista Savia Moderna en la calle de Santa Clara (1906); la emancipación sociocultural que cifra el Ateneo de la Juventud establecido, no sin articulados antecedentes, en 1909; y, por último, la emancipación socio-política raigal que desata la Revolución Mexicana estallada el siguiente año, 1910.

En el terreno específicamente literario, Revista Moderna (1898-1903), a la que seguirá la Revista Moderna de México (1903-1911), conecta no subterráneamente, sino a cielo abierto con El Renacimiento — movimiento y revista-, impulsado por mi paisano Ignacio Manuel Altamirano, y la obra breve, pero decisiva de Manuel Gutiérrez Nájera. Nombre que designa a un poeta, pero, asimismo, a un caudal poderoso que se vierte en el río en formación de las patrias letras. Hitos: sus poemas, cuentos, solitaria novela, artículos; Revista Azul a modo de buque insignia...

Sustentado ya - confío - el límite inferior, hago otro tanto - asimismo, conjetural intento - con el superior: 2000. Si a la historia nacional decimonónica la definen, en todos sus órdenes, Independencia y Reforma, al siglo xx lo define la Revolución. Ningún otro lance posterior cobrará estatura y empaque semejantes (reitero: para el xIx, Independencia y Reforma; para el xx, Revolución). Tanto que, en vez de estudios separados de su Corrido, Novela, Teatro, Pintura, Gráfica, deberíamos hablar de una Estética Revolucionaria, comprensiva - aglutinadora - de todas las especies mencionadas.

${ }^{20}$ En este punto difiero de lo propuesto por Clark de Lara. En su opinión, el último de los (también) cuatro cortes del XIx, que llama de la Modernidad, corre entre 1876 y 1911. En la mía, el xx literario arranca en 1898, al estimar que el Modernismo apareja una más de las emancipaciones que se inician en 1810-1821, justamente la de las letras, fuste de la poesía y la prosa, del todo manumitidas, del siglo xx. El siglo literario se adelanta al cronológico. 
De ahí que, en desmentida - desmedida - argucia de sus Intelectuales Orgánicos, haya quedado, a la postre, la intentona de llevar a esas alturas ya la Reforma Electoral de 1977, ora el triunfo electoral justamente el año 2000. Triunfo electoral del PAN — la Presidencia de la República en primer lugar-, partido fundado en 1939 como real oposición al PNR (1929), la "Revolución hecha partido político".

Si la LOPPE, instrumento legal de la Reforma Electoral, no oculta más sus costuras de unilateral medida de emergencia, con lo suyo de mayestática Gracia, de un sistema que perdía legitimidad - lo mismo ocurrirá con el Pacto Por México, pero ya en bola-, y acabó por procrear un sistema de representación traducido en Partidocracia, Partidos cuyos ilícitos intereses particulares bordean al Cártel; la victoria electoral de 2000 no aparejó Alternancia más Transición, sino alternancia "transa". Aunque, eso sí, lance incuestionable, sirvió de puntilla a la Des-Instauración de la Revolución Mexicana, en la que hoy por hoy nos debatimos, e iniciada en 1968. No sin faltar precedentes significativos.

¿Qué precedentes? Fuera del sistema, el sindicalismo independiente de maestros, y de ferrocarrileros entre otros gremios, al que puede - debe- sumarse el movimiento médico de 1965. Dentro del sistema, la frustrada reforma del PRI - Partido de Estado a la sazón-, encabezada por Carlos Madrazo. De su imposibilidad nacerá la Corriente Crítica del PRI, el PRD, el PT y MORENA.

\section{Contenidos}

La historia de la literatura mexicana del siglo xx requiere comprender tanto la "Literatura Literaria" — poesía, narrativa, ensayo - publicada entre 1898 y 1949, año de aparición del suplemento La Cultura en México del periódico, ya desaparecido, Novedades, como la "Literatura Periodística" publicada entre 1949 y 2000. Hablo, en el segundo caso, del fenómeno de escritores - en pleno dominio del oficio o debutantesejerciendo en suplementos, revistas y páginas culturales, principalmente, la crónica, el reportaje y las especies que, a partir de los 60's, despliega el New fournalism, versión local. No que, antes del 49, escasearan revistas literarias y suplementos culturales, a fin de cuentas, ambos subordinados al protagonismo del libro. De lo que hablo es del traslado del quehacer literario al medio periodístico, fin en sí, ajeno al libro en primera instancia, y consecuente con la preeminencia lograda por el estamento intelectual en el imaginario social, comparado, sobre todo, con Campesinos, Obreros y Sectores Populares, los preferidos de la Revolución Mexicana y sus expresiones artísticas principales.

"Literatura Periodística" de la que es diáfano precedente Monterrey, el correo literario con el que Alfonso Reyes intenta - en vano-, él en Sudamérica - Argentina, Brasil-, dialogar con sus adláteres. Soy de la opinión de que Monterrey no puede excluirse en el capítulo de precursores de la corriente que, a partir de 1949 — ya lo 
adelanté-, se profesionaliza en suplementos de la talla de La Cultura en México y su segunda parte México en la Cultura, y publicaciones como la Revista de la Universidad - de manera señalada entre 1956 y 1966-, Cuadernos del Viento, Plural, Nexos, Vuelta...

\section{Presupuestos}

O Bases. Presupuestos o Bases inexcusables, y con la Historia Intelectual ya franca tropa de refresco de los Estudios Literarios. Enumero los axiales.

a) Texto y contexto. No uno sobre o pese o en lugar del otro. Ambos. Pero con la recomendación - consigna, mejor dicho- de no perder de vista la especificidad literaria, manejo estético de la lengua o Literaturnost (para apropiarnos de una categoría del Formalismo Ruso). Se trate, respecto a esto último, lo mismo de la "Literatura Literaria" que de la "Literatura Periodística", arriba especificadas. De estricta aplicación resultan las prevenciones de LaCapra, y la dialéctica pasado-presente-pasado indicada por Dosse.

b) Sistema Literario (SL). Asunción cabal de las Instancias de Creación, Producción, Distribución, Recepción, Certificación (y, entre nosotros, por fortuna cada vez menos, Divinización). Tomando en cuenta los cambios en la libertad de creación, y posibilidades de edición y crítica, a raíz de uno de los efectos pos-68: la Guerra Sucia Cultural, que, amén de "desaparecer" - en el sentido que se le otorgará al narcotráfico- del canon, a causa de su incorrección política, a escritores seminales, gloria de cualquier literatura menos la nuestra en fundamentalista trance - que todavía dura-, introdujo con prácticas de inclusión/ exclusión, en términos de lealtades y adhesiones, y agencias como CONACULTA y FONCA - y ahora, sacada de la manga presidencial, una Secretaría de Cultura - profundas distorsiones en un proceso literario esencialmente decidido por el mérito y no la afiliación incondicional a tal o cual - suelo escribir "tal por cual" - facción en disputa por el poder cultural, contaminado por el poder a secas. Poder cultural traducido en influencia pública, cercanía al Príncipe y al Capital, control editorial - libros y revistas - y, en medios académicos, políticas de investigación y contratación.

De particular interés devendrá lo que llamo "oscilaciones de la Teoría" a lo largo del siglo, por sus implicaciones en Creación, Recepción y Certificación, principalmente. Las modas estructuralistas y post-estructuralistas, la post-modernidad, los "giros" de toda laya. ${ }^{21}$

c) Autor socialy/o colectivo. Sin demérito de genios y genialidades, pero enfatizándose el Sistema Literario, la "arqueología" del siglo xx literario pone el acento en los equi-

${ }^{21}$ Véase "Isagoge" (Curiel, 2019: 7-29). 
pos autorales. No es indispensable reputar los Ejes de la Historia para comprender su papel en la configuración de nuestra literatura - poesía y prosa - del siglo pasado (como las Asociaciones Literarias lo tuvieron en el antepasado). En equipo se inauguró el Modernismo, límite inferior, y como equipo alentó al siguiente, el Ateneo de la Juventud, y este último, a los siguientes barcos en tocar puerto, los Siete Sabios que se multiplicarán en la Generación de 1915, y los Contemporáneos. Y si a la suma Modernismo-Ateneísmo puede etiquetarse Primera Revuelta Cultural del siglo Xx, años del orto porfiriano y de inicios de la Revolución, la Segunda Revuelta se ciñe a los 60's — post-revolución, inicio de la des-instauración de la Revolución- - Tres fueron los equipos señeros. Los de Medio Siglo en madurez, y nacientes, los de Casa del Lago y/o Difusión Cultural, y La Onda. Análisis particular demandarán las promociones surgidas al filo o durante la Guerra Sucia Cultural por su ejercicio contencioso de los signos de influencia, protagonismo social-político, afiliación, pendencia, control de medios de expresión literaria.

Aclaración. Reconociendo la aportación mayúscula de la Idea Generacional de Ortega y Gasset, pero haciendo caso omiso de su exacta vara de medición, propongo su "remasterización". Ya no sólo Coetáneos y Contemporáneos con todo y la laxitud temporal reconocida a estos últimos, hacia atrás o hacia adelante (siete años). De lo que hablo es de Generaciones Típicas y Generaciones Atípicas. Coetáneas y Contemporáneas entre las primeras. De coyuntura, De época y Constelaciones entre las segundas. Como inevitable ejemplo de Constelación, la forma organizacional más dilatada, pongo al Ateneo de la Juventud. En un extremo, los casi abuelos Luis G. Urbina y Jesús Urueta. En otro, los bisoños Alfonso Reyes y Julio Torri. En medio, personeros de todas las edades. Es que la pertenencia generacional no la decide la cronología, erróneo parecer que todavía subsiste. Lo decide el programa en juego, y la libre decisión de hacerlo propio. Sin que dejen de influir determinados contextos: un episodio político o literario determinado, cierta lectura aglutinadora...

Si se me permite un dato personal, informo que mi generación temporal es la de La Onda, escritores nacidos durante la Segunda Guerra; pero que la electiva es la del Ateneo de la Juventud, que por cierto nunca se desintegró, no reglamentariamente hablando. La del Ateneo de la Juventud y, en parte, la de Medio Siglo. ${ }^{22}$

d) Modos y lugares de socialización. Organización intelectual, convivencia, redes, lecturas afines, simpatías y diferencias gregarias, ritualidad, banquetes, homenajes, conferencias y presentaciones de libros; tertulias, cafés, cantinas, restaurantes.

${ }^{22}$ La "parte" que todavía se proponía la crítica positiva de la Revolución Mexicana, antes de que la bocabajearan deslumbrados por la Cubana. ¿Por ser obra de intelectuales y ceñirse pronto a un sistema de ideas, que resultó ser el del marxismo? 
e) El Humanismo. La obligada reinserción permanente de la Literatura en su matriz, las Humanidades, sobre todo, en su "núcleo duro": Literatura, Filosofía, Historia.

f) Sincronía y diacronía. Una y otra en permanente maridaje dialéctico.

g) Re-significación de la Literatura del $\Upsilon_{0}$. En tiempo real: diarios, epistolarios, informes, entrevistas, sin desdeñar las exclusivamente publicitarias o "banqueteras"; y en tiempo figurado o memorioso: autobiografias, memorias, evocaciones de época y recuerdos personales.

h) Especial atención a la Ciudad. Plaza a tomar por el Autor Social. La Ciudad Modernista, la Ciudad Atenea, la Ciudad Vanguardista, la Ciudad de los Talleristas, la Ciudad del Medio Siglo, etcétera.

i) Periodización literaria en el marco -y cotejo- de la historia general.

\section{Técnica operacional}

Lector, lectora: el último inciso de la lista anunciada nos conduce al procedimiento - los procedimientos - a seguir. Experiencia personal. Suelo, en primer término, realizar cortes en el cuerpo a examen, un siglo de literatura, 1898-2000. Esto en relación con los cortes temporales de la historia general en la que la específicamente literaria se inserta. Cortes los de la historia general que arrojan: Tardoporfirismo, Revolución, Post-Revolución y Des-Instauración de la Revolución Mexicana. Y por lo que atañe a la historia literaria: modernismo-ateneísmo, vanguardias, nacionalismo, cosmopolitismo, literatura de mercado.

Fijado lo anterior, procedo a un doble escudriñamiento. De un lado, el de los equipos en contienda: el hegemónico, el que está por hacer mutis, y el "reciénvenido". De otro, el de los manifiestos también en contienda: el estético-literario, el educativo, el social, el hispanoamericano. Fundamental guía es el distingo alfonsino entre antecedencias, concomitancias y consecuencias. Por último, avanzo, divido las escalas en la hechura de nuestras letras del xx, a saber:

1898-1924; 1924-1940; 1940-1968; y, por último, 1968-2000.

Cortes que, al tenor de la imposible exactitud matemática en las disciplinas $\mathrm{Hu}-$ manistas, reconocen yuxtaposiciones y traslapes, anticipos y corrimientos, fronteras temporales en movimiento.

\section{Escalas}

Por último, decía, en concomitancia con los cortes - y su contenido - señalados para la historia general del siglo xx mexicano, procedo a describir someramente - tentativamente - cada una de las cuatro escalas (o cortes, o periodos) de la específica historia literaria. 
La primera escala, reitero, corre entre 1898, arranque por las razones antes expuestas del siglo literario, y 1924 (o, añado, 1925), término de la doble movilización cultural y educativa, la privada del Ateneo de la Juventud y la pública del vasconcelismo a nombre de la Revolución (en sentido estricto, de la facción revolucionaria triunfante a la sazón, la de Agua Prieta). Periodo en el que fragua el Modernismo, irrumpe dentro y fuera de México la literatura atenea - enemiga de la preceptiva de los géneros, compartimentos estancos-, surge la Novela de la Revolución con Mariano Azuela, rutila inconfundible y se extingue la estrella de Ramón López Velarde. En Madrid, Alfonso Reyes se alza formidable escritor variopinto, en horas de autodestierro. ${ }^{23} \mathrm{Y}$ aquí, dos escritores de la camada atenea, no menos excepcionales y modernos: Julio Torri y Mariano Silva y Aceves. Temporalidad la comentada en la que, asimismo, tiene su lugar el novelista porfirista — él habla de "porfirismo interior"-, Federico Gamboa y su Santa; novela inmensamente popular, entonces y después y ahora mismo, pese al retobo académico apenas en años recientes doblado por la evidencia y el sano juicio.

En el terreno de las revistas, El Maestro, Pegaso, La Nave, etcétera, y la extinción primero de Revista Moderna de México (1911) y después de la Revista Positiva (1914).

Primera escala, pues.

\section{Segunda escala}

De 1924(25) a 1940, año este último normalmente reconocido como el primero de la post-Revolución. Principales grupos: el de los Siete Sabios, mismo que, en famoso ensayo de uno de ellos, Manuel Gómez Morín, formara como simiente la vasta Generación de 1915; los Contemporáneos; y los Estridentistas. Tríada que en nuestra óptica temporal integra a la(s) Vanguardia(s); movimiento reconocible tras la Primera Revuelta Cultural del siglo xx, la de Modernistas y Ateneístas. Y en cuanto a las Ideas, Manifiestos e Ismos numerosos: nacionalismo, indigenismo, proletarismo, folklorismo, neocolonialismo; incluso, un espíritu ateneo que se mantiene contra la diáspora del grupo, decidida tanto por elecciones íntimas como por las impuestas por la lucha de facciones revolucionarias, lucha feroz que no cancela la construcción del Nuevo Estado Revolucionario, por oposición al Estado Liberal del Porfiriato. En 1929, se concede la autonomía a la Universidad Nacional de México; compensación, de algún modo, a la derrota electoral de José Vasconcelos, exrector - y primer titular de la Secretaría de Educación Pública-, en su aspiración de ocupar la Presi-

\footnotetext{
${ }^{23}$ Prefiero autodestierro, u obligado destierro, cuando la persona se traslada a un país que, por lo menos, habla el mismo idioma de su país natal. Dejo, en cambio, exilio para la extrañeza, extranjería - desamparo - totales.
} 
dencia de la República. Surge la Editorial Cultura. Alfonso Reyes regresa en definitiva a México. Se crea la Casa de España, al punto, al socaire de las críticas levantadas por la medida, mudada a El Colegio de México, mudanza que no altera el objetivo original: dar refugio, acogida a los científicos, intelectuales y escritores españoles a la caída de la Segunda República.

\section{Tercera escala}

De 1940 a 1968, año este último, si no "parteaguas" de la historia nacional, sí de inflexión para el sistema político. Mitificada en extremo su "lectura", el 68 oculta, empero, el bosque de la Segunda Revuelta Cultural en la escena mexicana a lo largo de casi todos los años sesenta; revuelta en las artes todas y el pensamiento, en la que la literatura ocupa papel protagónico. Pero, como señala Emmanuel Carballo, en puntos nodales, los años sesenta son inexplicables sin los cincuenta y, me temo, los cincuenta sin los cuarenta. Intencional perogrullada.

El periodo de la post-Revolución acentúa dos características, la urbanización y la industrialización, que influyen de manera definitiva en la factura ascendente del estamento intelectual, en el que se inscriben las letras. En los cuarenta, además de la Casa de España, enseguida El Colegio de México, se funda El Colegio Nacional, se crean los Premios Nacionales y se pone fin al caos universitario derivado del intento gubernamental de privatizarla en 1933, con la promulgación de la Ley Orgánica de 1945. En 1947, aparece Al filo del agua, novela de Agustín Yáñez que, en la tradición de Los de abajo y La sombra del caudillo, funge de apertura brillante de la modernidad narrativa.

En los cincuenta, se visibilizan los nombres de José Revueltas, Juan José Arreola, Juan Rulfo, principalmente, e irrumpe, en la Facultad de Derecho trasladada a Ciudad Universitaria - CU inaugurada en 1952-, la Generación de Medio Siglo. Influido por José Gaos, Leopoldo Zea encabeza el grupo de filósofos, autobautizado Hiperión y empeñado en el ser y hacer del Mexicano. Línea de reflexión que se remonta a Ezequiel A. Chávez y a Samuel Ramos, incluye a Octavio Paz, e inaugura su colección con $\mathrm{La}$ " $X$ " en la frente de Alfonso Reyes. ${ }^{24}$ Nace, correspondencia de las artes, Poesía en Voz Alta. En 1959, se inaugura la Casa del Lago al amparo de la UNAM.

Ya lo adelanté. En su conjunto, los sesenta escenifican la Segunda Revuelta Cultural del siglo xx mexicano. Si en la literatura alcanza madurez la hornada del Medio Siglo, irrumpen dos generaciones más, la de Casa de Lago y/o Difusión Cultural y la de La Onda, mientras el capítulo mexicano del Boom lo acapara Carlos Fuentes; semejante ebullición tiene lugar, asimismo, en el teatro, en la pintura y en la cinema-

${ }^{24}$ Entre 1952 y 1955, la casa Porrúa y Obregón publica la colección "México y lo mexicano", con los trabajos del grupo Hiperión, a los que se suma Reyes. 
tografía. Hablo, respectivamente, del Teatro Experimental Universitario, de La Ruptura y del grupo Nuevo Cine. Innovación que alcanza a la música de concierto y a las artes gráficas (Snob de Salvador Elizondo, entre otras revistas). Arrancan los catálogos de Mortiz, Era y Siglo XXI.

En 1967, Mortiz publica La Mafia de mi entrañable Luis Guillermo Piazza, burlas veras del ascenso social del estamento intelectual.

\section{Cuarta escala}

1968-2000. Reconozco, por su cercanía temporal, y que aún perduran no pocos de sus rasgos, la dificultad de tipificarla. ¿Qué rasgos? En primer término, una Guerra Sucia Cultural, contienda entre facciones - ¿tres, dos en realidad por la similitud entre dos de ellas?-, que llamo así por equipararla a la Guerra Sucia con la que el "sistema" reprimió la vía armada - guerrillas - con la que algunos grupúsculos respondieron al 2 de octubre en Tlatelolco. Un factor metaliterario, la corrección política, de izquierda - entiéndase lo que se entienda entre nosotros por izquierda-, y liberal - con indudable corrimiento a la derecha-, tomó el lugar de la valoración estética. Factor que decidió la "desaparición", el "encobijamiento" de escritores decisivos. Larga lista en la que sobresalen los nombres del ateneísta Martín Luis Guzmán, de los Contemporáneos Jaime Torres Bodet y Salvador Novo, de Agustín Yáñez, de Mauricio Magdaleno, de Rafael Solana, de Luis Spota. Borrado extremo: en la crítica y en la estimación pública y, ahí donde se tenía injerencia en la investigación institucional, en los planes y programas, en los rescates y aun en congresos y simposios.

En contraposición, se instalaron organismos de Certificación, como el CONACYT, CONACUlTA, el Fonca, el Sistema Nacional de Creadores, que modificaron en su raíz el tradicional hábitat cultural, artístico y literario. Sólo que, en la medida que crecía este "aparat", presupuestal, becario, de incentivos de todo orden, se constreñían los circuitos de librerías, editoriales alternativas y, me temo, lectores. El estamento intelectual proveyó, además, en tanto intelectuales orgánicos — digámoslo-, a esos dos episodios, la Reforma Política y la Alternancia (que no transición) del 2000, a los que en vano se intentó otorgar rango de episodios revolucionarios nacionales.

Insisto en la difícil caracterización de este periodo. Me limito a adelantar dos hechos documentados y un indicio. Pese al desuso, inclusive descrédito, de la perspectiva generacional, durante esta escala surgen dos equipos rematadamente generacionales, el Crack y Los Enterradores.

El indicio expresa la derrota - por fortuna no definitiva-, en el ámbito editorial, de la Ley de la Solidaridad y del Riesgo Estéticos, a manos de la Ley de la Rentabilidad.

En fin, pocas como esta escala reclaman el concurso, y polémica, de pareceres. 


\section{Coda}

¿Empresa, la de la historia intelectual aquí propuesta, de un solo investigador? No. Empresa colectiva, más aún, amén de inter-disciplinaria, quizá multi-institucional. Fórmula, esta última, por cierto, probada con ventura en la edición del vasto Diario de Alfonso Reyes (1912-1959), que concitó la colaboración de varias instancias; desde esta Máxima Casa de Estudios hasta el Fondo de Cultura Económica, su casa editora, pasando por la Academia de la Lengua, la Universidad Autónoma Metropolitana y la Capilla Alfonsina. ${ }^{25}$ Proyecto coordinado por José Luis Martínez, con la asistencia de Alicia Reyes.

Hablo, en fin, del concierto de filólogos — en la connotación de la filología como amalgama de literatura y lingüística-, historiadores, investigadores sociales, filósofos, urbanistas (y urbanitas). Empeñados al unísono en el propósito que perseguía "Sócrates" Henríquez Ureña (Pedro): seguir las corrientes relacionadas con "la búsqueda de nuestra expresión", la "expresión” de un México que no termina de configurarse, pese a Independencia, Reforma y Revolución; panorama literario integrado no sólo por la superior belleza lograda en la punta del iceberg, sino en su entero cuerpo y las aguas que lo circundan y proporcionan.

Plenamente conscientes, unos y otros, de las completas relaciones - en veces peligrosas - entre Literatura e Historia.

Frontera, fronteras sería la divisa insignia. Concepto, tal y como lo juzga George Steiner. Doble categoría: conocimiento de punta, de avanzada, y lugar de encuentro de diversas disciplinas (véase Steiner: 10).

Hasta aquí (puntos suspensivos) por ahora.

\section{Bibliografía}

Cervantes, Miguel de

El ingenioso hidalgo don Quijote de la Mancha. Prólogo y esquema biográfico de Américo Castro.

México: Porrúa, 2017.

Glark de Lara, Belem

Letras mexicanas del XIX. Modelo de comprensión histórica. México: Universidad Nacional Autónoma de México, Instituto de Investigaciones Filológicas, Seminario de Edición Crítica de Textos, 2009.

Clark de Lara, Belem y Fernando Curiel Defossé

"Filología literaria", en Belem Clark de Lara y Fernando Curiel (coordinadores). Filología

${ }^{25}$ En realidad, Alfonso Reyes emprende el Diario - en forma y constancia - a partir de 1924, si bien más adelante incorporará escritos directa o indirectamente alusivos a episodios anteriores, en particular los relativos a la participación de su padre en la política maderista. De manera señalada, lamentará no haber llevado un diario de sus decisivos años madrileños. 


\section{sigloveinte@lit.mex. Recorrido en 4 escalas}

mexicana. Prólogo de Belem Clark de Lara y Fernando Curiel. México: Universidad Nacional Autónoma de México, Instituto de Investigaciones Filológicas, 2001, 77-110 (Ediciones Especiales, 23).

Curiel Defossé, Fernando

"Ambición sin límites. La intelectualidad mexicana del siglo xx", en Historia y Grafia. El vago objeto de la escritura: los intelectuales en su laberinto. México: Universidad Iberoamericana, número 23 (2004), 55-94.

Hábitos. México: Universidad Nacional Autónoma de México, Coordinación de Humanidades, 2005.

sigloveinte@lit.mx.Amplio tratado de perspectiva generacional. México: Universidad Nacional Autónoma de México, Coordinación de Humanidades, 2008.

"Tropas de refresco. Ensayo de historia literaria patria", en Literatura Mexicana, volumen XXVI, número 2 (2015), 97-123.

"Historia y literatura", en (an)ecdótica, sección "Reflexiones en torno a...", volumen II, número 1 (enero-junio de 2018), 9-14.

Novo conoce el mar y otros ensayos. México: Universidad Nacional Autónoma de México, Instituto de Investigaciones Filológicas, Seminario de Edición Crítica de Textos, 2019 (Resurrectio VI. Estudios, 6).

Curiel Defossé, Fernando, Carlos Ramírez y Antonio Sierra

Índice de las revistas culturales del siglo XX (Ciudad de México). México: Universidad Nacional Autónoma de México, 2007.

Guriel, Fernando, Virginia Guedea, Guillermo Hurtado y Humberto Muñoz

"Reconocimiento, encomio y defensa de las Humanidades", en Las humanidades en el Conacyt. Un manifiesto. Consultado en: http://www.iifilologicas.unam.mx/index.php? page=las-humanidades-en-el-conacyt-un-manifiesto [08/06/2019].

Cusset, François

French theory. Foucault, Derrida, Deleuze Ë Cia. y las mutaciones de la vida intelectual en Estados Unidos. Traducción de Mónica Silva Nasi. Barcelona: Melusina, 2005.

Dosse, François

La historia: conceptos y escrituras. Buenos Aires: Nueva Visión, 2004.

EsPinASA, José María

La literatura mexicana del siglo Xx. México: El Colegio de México, 2015 (Historias Mínimas).

García Ruiz, Alicia

"Prólogo", en Dominick LaCapra, La historia y sus limites. Humano, animal, violencia. Traducción de Francisco Ramos Mena. Barcelona: Bellaterra, 2016. 


\section{Henríguez Ureña, Pedro}

"Advertencia", en Antología del Centenario. Estudio documentado de la literatura mexicana durante el primer siglo de la Independencia (1800-1821). Obra compilada bajo la dirección del maestro Justo Sierra por Luis G. Urbina, Pedro Henríquez Ureña y Nicolás Rangel. Primera parte, I. Presentación de Porfirio Martínez Peñaloza. México: Universidad Nacional Autónoma de México, 1985.

LACAPra, Dominick

La historia y sus limites. Humano, animal, violencia. Traducción de Francisco Ramos Mena. Barcelona: Bellaterra, 2016.

LYOTARD, Jean-François

La condición postmoderna. Informe sobre el saber. Traducción de Mariano Antolín Rato. Barcelona: Planeta-Agostini, 1999.

Memoria UNAM 1994

Consultado en: planeacion.unam.mx/Memoria/anteriores/1994/iifl.php [13/06/2019].

O’Gorman, Edmundo

"Fantasmas de la narrativa", en Eugenia Meyer (editora). Imprevisibles historias. En torno a la obra y legado de Edmundo O’Gorman. Estudio preliminar de Eugenia Meyer. México: Universidad Nacional Autónoma de México, Facultad de Filosofía y Letras, Fondo de Cultura Económica, 2009, 951-958 (Vida y Pensamiento de México).

PALti, Elías José

Giro lingüístico e historia intelectual. Buenos Aires: Universidad Nacional de Quilmes, 1998.

Reyes, Alfonso

Pasado inmediato y otros ensayos. México: El Colegio de México, 1941.

“Correspondencia. Crítica epistolar”, en El Hijo Pródigo, volumen XII (abril-junio de 1946). Edición facsimilar. México: Fondo de Cultura Económica, 1983 (Revistas Literarias Mexicanas Modernas), 78-79.

Ricoeur, Paul

Tiempo y narración. Tomo I. México: Siglo XXI, 1995.

RORTY, Richard

El giro lingüístico de la filosofia. Barcelona: Paidós, 1990.

SokAL, Alan y Jean BricmonT

Impostures intellectuelles. Paris: Editions Odile Jacob, 1997.

STEINER, George

Sobre la dificultad y otros ensayos. Traducción de Adriana Margarita Díaz Encino. México: Fondo de Cultura Económica, 2006. 